\title{
A TRÍADE DA REFORMA DO ENSINO MÉDIO BRASILEIRO: LEI № 13.415/2017, BNCC E DCNEM
}

\author{
KOEPSEL, ELIANA CLÁUDIA NAVARRO ${ }^{1}$ \\ ORCID: https://orcid.org/0000-0002-0429-4160 \\ GARCIA, SANDRA REGINA DE OLIVEIRA ${ }^{2}$ \\ ORCID: https://orcid.org/0000-0002-6684-181X \\ CZERNISZ, ELIANE CLEIDE DA SILVA 3 \\ ORCID: https://orcid.org/0000-0002-4317-6052
}

\begin{abstract}
RESUMO: O texto discute a relação entre a Lei n. ${ }^{\circ}$ 13.415/2017, a Base Nacional Comum Curricular BNCC - e as Diretrizes Curriculares Nacionais para o Ensino Médio - DCNEM. Com aporte em discussão bibliográfica e documental, analisa a reforma do ensino médio, destaca as audiências públicas, evidencia os elementos controversos na proposta para formação e expõe a vinculação dessa proposição com os organismos internacionais no direcionamento neoliberal. Como resultados, aponta que a reforma traz traços reacionários e de acentuação da desigualdade educacional que impactam a formação da juventude e o trabalho desenvolvido pela escola. É um assunto importante a ser analisado por todos os professores que visam ao desenvolvimento da educação média para a formação emancipadora da juventude brasileira, num trabalho que leve em conta a compreensão do sujeito jovem enquanto ser social.
\end{abstract}

Palavras-chave: Política Educacional, Ensino Médio, BNCC.

\section{THE TRIAD OF THE BRAZILIAN HIGH SCHOOL REFORM: LAW № 13.415/2017, BNCC AND DCNEM}

ABSTRACT: The text discusses the relationship between Law No. 13.415/2017, the National Common Curricular Base - BNCC, and the National Curricular Guidelines for Secondary Education - DCNEM. Based on bibliographical and document discussion, the article analyzes high school reform; highlights the public hearings; points out the controversial elements in the training proposal and shows the relation of this proposition with international bodies in a neoliberal direction. As results, we indicate that the reform has reactionary traits and accentuates educational inequality that impact youth formation and the work developed by school. It is an important issue to be analyzed by all teachers that aim the development of High School education for the emancipatory formation of Brazilian youth, in a work that understands youngsters as social beings.

Keywords: Educational Policy, High School, BNCC.

\footnotetext{
${ }^{1}$ Universidade Estadual de Maringá (UEM). Maringá, PR, Brasil. <ecnkoepsel@uem.br>

2 Universidade Estadual de Londrina (UEL). Londrina, PR, Brasil.<sandragarcia@uel.br>

${ }^{3}$ Universidade Estadual de Londrina (UEL). Londrina, PR, Brasil. <eczernisz@uel.br> Educação em Revista|Belo Horizonte|v.36|e222442 |2020
} 


\title{
LA TRÍADA DE LA REFORMA DE LA ENSEÑANZA MEDIANA BRASILEÑA: LEY № 13.415/2017, BNCC Y DCNEM
}

\begin{abstract}
RESÚMEN: El texto discute la relación entre la Ley n. ${ }^{\circ}$ 13.415/2017, la Base Nacional Común Curricular - BNCC y las Directrices Curriculares Nacionales para la Enseñanza Mediana - DCNEM. Con contribución en discusión bibliográfica y documental, analiza la reforma de la enseñanza mediana, destaca las audiencias públicas; evidencia los elementos polémicos en la propuesta para formación y expone la vinculación de esta proposición a los organismos internacionales en el direccionamiento neoliberal. Como resultados, apunta que la reforma trae rasgos reaccionarios y de acentuación de la desigualdad educacional que impactan la formación de la juventud y el trabajo desarrollado por la escuela. Es un tema importante de analizar por todos los profesores que visan al desarrollo de la educación mediana para la formación emancipadora de la juventud brasileña, en un trabajo que toma en cuenta la comprensión del sujeto joven, mientras un ser social.
\end{abstract}

Palabras clave: Política educacional, Enseñanza Mediana, BNCC.

\section{INTRODUÇÃO}

Este texto analisa a reforma do ensino médio, a qual consolida as mudanças almejadas pelo governo, a despeito das manifestações contrárias aos rumos que se impõem ao ensino médio brasileiro. Com foco em três documentos - a Lei n. ${ }^{\circ}$ 13.415/2017, a Base Nacional Comum Curricular (BNCC) e as Diretrizes Curriculares Nacionais para o Ensino Médio (DCNEM) -, este estudo bibliográfico e documental tem como objetivo identificar o impacto dessa tríade nas perspectivas de futuro da juventude brasileira, buscando destacar aspectos gerais da BNCC, a relação entre sua proposta e os direcionamentos externos para a política educacional brasileira, os elementos considerados importantes para a formação do estudante do ensino médio e os limites postos com a nova/velha perspectiva curricular. Em nosso entendimento, a Medida Provisória (MP) n. ${ }^{\circ}$ 746/2016 e seus desdobramentos ( Lei n. ${ }^{\circ}$ 13.415/2017, BNCC e DCNEM/Parecer n. ${ }^{\circ}$ 03/2018 CNE/CEB) constituem um rompimento das discussões que datam de 2011, das críticas e propostas alternativas, construídas desde a proposição do PL n. ${ }^{\circ}$ $6.840 / 2013$.

Trata-se de um assunto importante pelo fato de que a BNCC norteará o desenvolvimento do ensino e da aprendizagem, redirecionando o trabalho pedagógico escolar, a formação dos estudantes e, também, a de professores para atuar no ensino médio.

A BNCC para o ensino médio, publicada em 2018, provoca discussões e questionamentos diversos, porque a razão de sua proposição é completar a reforma inicialmente apresentada como Medida Provisória (MP) n. ${ }^{\circ}$ 746/2016, intensamente questionada e rejeitada por inúmeros brasileiros que entenderam ser este encaminhamento inapropriado para uma alteração curricular numa sociedade que, considerada democrática, ao menos deveria ter tido a oportunidade de discuti-la. Para nós, a MP foi o primeiro ato antidemocrático, cuja continuidade se deu quando o MEC encaminhou a sua versão de BNCC para o Conselho Nacional de Educação (CNE), interrompendo a discussão que vinha sendo travada, e finalizou com a aprovação da atualização das DCNEM.

A rejeição a esta reforma tem sido explicitada no resultado das Audiências Públicas realizadas pelo Conselho Nacional de Educação, as quais têm evidenciado que ela não agradou ao MEC e ao próprio CNE, pois a maioria dos participantes, nos três minutos regimentais disponíveis para expor oralmente suas posições, pôde denunciar os limites incontornáveis da proposta e, portanto, defender a revogação da Lei n. ${ }^{\circ}$ 13.415/2017 e a não aprovação da BNCC. Para tentar amenizar o resultado das Audiências do CNE, o MEC/CONSED abriu uma consulta em 2 de agosto de 2018, denominado de o dia "D" da BNCC do Ensino Médio, para tentar legitimar, através de uma pseudoparticipação, a proposta apresentada. 
Em vista disso, entendemos que todo esse processo precisa ser discutido e compreendido, a fim de se avaliar o encaminhamento da política educacional para o ensino médio. Desse modo, organizamos este texto, discutindo, inicialmente, a Medida Provisória, a Lei n. ${ }^{\circ}$ 13.415/2017, a BNCC e, atualmente, as DCNEM. Em seguida, abordamos o contexto de produção e discussão da BNCC em audiências públicas que explicitam o descompasso da política educacional. Na sequência, mencionamos a influência dos organismos internacionais na definição do currículo, na formação e na escola que minimiza o ensino médio, aprofundando o dualismo escolar. Finalizamos, então, comentando a aprovação às DCNEM, ação que completa a tríade.

\section{MEDIDA PROVISÓRIA, LEI N. 13.415/2017 E BNCC}

A medida provisória, que tem força de lei, é um instrumento utilizado pelo Presidente da República, em casos de relevância e urgência. Empenhado em justificar tal expediente, o Ministro de Estado da Educação encaminhou ao presidente da República 24 pontos que justificariam a proposição da MP n. ${ }^{\circ}$ 746. Logo no primeiro item, afirma o ministro que a MP proposta visa à:

[...] alteração da Lei no 9.394, de 20 de dezembro de 1996, que estabelece as Diretrizes e Bases da Educação Nacional - LDB, para dispor sobre a organização dos currículos do ensino médio, ampliar progressivamente a jornada escolar deste nível de ensino e criar a Política de Fomento à Implementação de Escolas de Ensino Médio em Tempo Integral (BRASIL, 2016b, p. 1 grifos nossos).

O ministro, ao afirmar que, nessa etapa de ensino, "[...] a sua função social, prevista no art. 35, não atingiu os resultados previstos" (BRASIL 2016b, p. 1), evidencia um descompasso entre o pretendido e o alcançado e informa que a sua correção seria possível com a diversificação do currículo, com o oferecimento de um currículo menos extenso, mais atrativo, que estabeleceria um diálogo com a juventude e a induziria ao desenvolvimento de habilidades e competências. A proposta apresentada pelo ministro parece se assentar, principalmente, numa "correção", qual seja, na alteração curricular. Repetidas vezes, afirma que o problema é que, no Brasil, tem-se a obrigação de cursar "treze disciplinas obrigatórias" (BRASIL, 2016b, p. 1-2).

É preciso lembrar, no entanto, que a MP n. ${ }^{\circ} 746$ foi apresentada rapidamente, pois teve o PL n. ${ }^{\circ}$ 6.840/2013 como proposta base, lapidada por consultores do CONSED, dentre eles, Maria Helena Guimarães Castro, que se tornou Secretária Executiva do MEC em 2016.

Quando a MP n. ${ }^{\circ}$ 746/2016 chegou ao Congresso Nacional, foi criada uma Comissão Mista, formada por deputados e senadores, para aprovar um parecer sobre a Medida Provisória. Em 30 de novembro de 2016, foi publicado o Parecer n. ${ }^{\circ}$ 95, de 2016-CN, do Relator, o Senador Pedro Chaves. O parecer emitido por esta Comissão considerou que a proposição da pretendida reforma do ensino médio, pela medida provisória, se encontrava amparada na justificativa dos requisitos de "urgência" e "relevância", como se até então nenhuma proposta estivesse sendo discutida.

O referido parecer enumera um conjunto de problemas que estariam impulsionando a reforma do ensino médio e repete as argumentações já expostas pelo Ministro da Educação ao encaminhar a MP, quais sejam: o contingente de jovens fora da escola; os baixos escores do ensino médio no Índice de Desenvolvimento da Educação Básica (Ideb); a falta de infraestrutura das escolas; a ausência de "conexão com a vida real", no aspecto curricular - " $82 \%$ dos jovens na idade entre 18 e 24 anos estariam fora do ensino superior" (BRASIL, 2016d, p. 09). Afirma, ainda, que os jovens que estão estudando se encontram em "salas de aula precarizadas, ouvindo aulas maçantes e enciclopédicas, sem perspectiva para o futuro" (BRASIL, 2016d, p. 09). Depois de arrolar os problemas dessa etapa de ensino, o parecer relaciona as razões para tal proposta: atribuir atratividade ao ensino médio; atender aos projetos de vida dos jovens; conectar o ensino às demandas do processo de desenvolvimento do País; e aumentar os resultados de proficiência e diminuir o abandono (BRASIL, 2016d).

Assim, o "novo" pretendido encontra-se fundamentado principalmente nas promessas de "valorização do protagonismo juvenil" e na "flexibilidade curricular" (BRASIL, 2016d, p. 11). A escolha 
dos itinerários formativos é a promessa e a aposta de que todo estudante "[...] poderá fazer escolhas, conforme seu projeto de vida e de seus horizontes" (BRASIL, 2016d, p. 11), ainda que o texto também afirme que o caminho não é tão direto assim, pois é dependente da definição das redes de ensino. $\mathrm{O}$ mecanismo que possibilitaria essa oportunidade se amparava nos itinerários formativos, definidos na Base Nacional Comum Curricular, a qual se encontrava, à época, em versão preliminar.

Muitas críticas e questionamentos foram feitos à medida provisória. Para Cunha (2017), a despeito das promessas de inovação, novidade que se busca insistentemente afirmar nos textos oficiais e oficiosos, o que está ocorrendo é uma reedição da reforma educacional dos anos 1990:

Não se trata de invenção de ministro improvisado. Trata-se, isto sim, da reedição da política educacional discriminadora do período Fernando Henrique Cardoso, quando Maria Helena Guimarães de Castro ocupou a presidência do Instituto Nacional de Estudos e Pesquisas Educacionais durante toda sua gestão, após dirigir secretarias nos governos paulistas de José Serra e Geraldo Alkmin (CUNHA, 2017, p. 7).

Nessas propostas, o papel atribuído pelo Estado à educação é a realização dos potenciais da juventude, enquanto "fenômeno essencial para o desenvolvimento sustentável do País" (BRASIL, 2016, p. 09). Apoiado numa ideia de liberdade de escolhas, sua efetivação dar-se-ia pela possibilidade de realização do projeto de vida do indivíduo, conforme sua vontade e suas potencialidades via escolha de itinerários formativos. A suposta "liberdade de escolha" pauta-se no ideário de possibilidade de efetivação do princípio da doutrina liberal pela viabilidade da "sociedade aberta" (CUNHA, 1986, p. 55), na qual potencialidades e motivações distintas determinariam a estrutura ocupacional na sociedade, e não a sua condição de origem:

A corrente liberal postula que os indivíduos nascem com potencialidades distintas e têm diferentes motivações. Eles devem se posicionar na estrutura ocupacional das sociedades conforme suas potencialidades e sua motivação e não de acordo com a posição que ocupa pelos pais (CUNHA, 1986, p. 21).

O pressuposto liberal que ampararia a ideia de liberdade de escolha, projeto de vida e protagonismo, a nosso ver, nasce morto na Lei n. ${ }^{\circ} 13.415 / 2017$, porque cada sistema de ensino vai apresentar itinerários cuja combinação é dependente da disponibilidade orçamentária e de recursos materiais e humanos por parte dos sistemas de ensino (BRASIL, 2017). Uma vez que a oferta de itinerários está condicionada às possibilidades de cada sistema de ensino, é a partir daquilo que cada sistema federado dispuser que o jovem vai acomodar a sua "escolha" ou o seu "projeto de vida". Dessa forma, no ponto de partida não existe qualquer alternativa a não ser a acomodação à disponibilidade de recursos, pelo menos para aqueles que dependem da educação pública, num contexto de contenção de investimentos públicos - face ao que é posto pela reforma fiscal na Emenda Constitucional n. ${ }^{\circ}$ 095/2016, que proíbe por vinte anos o aumento de qualquer cifra para investimento financeiro em políticas sociais. As classes que puderem arcar com os custos da educação certamente buscarão alternativas. As demais ficarão restritas às opções definidas pelos sistemas de ensino. O sonho e a vontade de cada sujeito, conforme proclamado, só poderão ser cultivados a partir de condições muito determinadas, inclusive em termos de conteúdo, ao se priorizarem determinados componentes curriculares e se preterirem outros.

Outra questão a ser refletida pauta-se sobre a organização curricular em estudos e práticas. De acordo com a legislação em vigor, "A Base Nacional Comum Curricular referente ao ensino médio incluirá obrigatoriamente estudos e práticas de educação física, arte, sociologia e filosofia” (BRASIL, 2016a). Questiona-se, em primeiro lugar, a secundarização de artes, educação física, sociologia e filosofia, as quais, de disciplinas, passam a ser estudos e práticas; e, em segundo lugar, a centralidade em disciplinas de português e matemática. Há que se perguntar: o que significam estudos e práticas? Quem vai definilos? Na Resolução n. ${ }^{\circ}$ 03/2018 das DCNEM, estudos e práticas são assim tratados:

Art. $11 \int 5^{\circ}$ Os Estudos e práticas destacados nos incisos de I a IX do $\int 4^{\circ}$ devem ser tratados de forma contextualizada e interdisciplinar, podendo ser desenvolvidos por projetos, oficinas, 
laboratórios, dentre outras estratégias de ensino e aprendizagem que rompam com o trabalho isolado, apenas em disciplinas (BRASIL, 2018b).

Observa-se ausência de definição do que consistem estudos e práticas na substituição do campo disciplinar, já que a disciplina também pode ter o mesmo tratamento que é descrito no $\ 5 .^{\circ}$ do art. 11 das Diretrizes Curriculares Nacionais para o Ensino Médio. Além de tais questões, apontamos outros aspectos que merecem consideração: os itinerários formativos que, conforme indica a Lei, são definidos pela rede de ensino e pelas escolas, sendo as possibilidades de formação divulgadas pela mídia governamental que, supostamente, deixa limitadas perspectivas de escolha pelos estudantes para sua trajetória profissional; a presença do notório saber nas escolas, atuando no processo de ensino, demonstra tanto o enaltecimento de saberes relacionados à prática, ao espaço extraescolar, como também o incentivo à participação de voluntários não docentes no processo de ensino, fator que nos leva a questionar o papel atribuído à escola pelos inspiradores da nova Lei; a janela oportunista que se abriu, por exemplo, sobre a docência, visto que o Parecer n. ${ }^{\circ}$ 95/2016 informa que se beneficiou da "[...] oportunidade para retirar do art. 62 da LDB a exigência de que apenas em universidades e institutos superiores de educação se faça a formação de docentes em nível superior para atuar na educação básica" (BRASIL, 2016a); e a formação em jornada integral no ensino médio, ação que, para não ser um improviso em condições já bem precárias, requer financiamento, em um contexto de contenção de investimentos públicos face ao que é preconizado pela Emenda Constitucional n. ${ }^{\circ}$ 095/2016.

Os elementos acima descritos - o estabelecimento de hierarquia entre disciplinas, um contexto de contenção de investimentos públicos e a definição de itinerários formativos condicionada às possibilidades existentes de cada sistema de ensino - oferecem-nos pistas das incertezas relacionadas à implementação da Lei n. ${ }^{\circ}$ 13.415/2017. Para além desses problemas, a lei foi aprovada, mesmo se sabendo que o que lhe dava corpo e alma era a BNCC, documento publicizado e só posteriormente aprovado (05/12/2018). É importante retomar o percurso de desenvolvimento da BNCC.

Em 2011, após a aprovação do conjunto de Diretrizes Curriculares da Educação Básica (DCNEB), as novas Diretrizes Curriculares Nacionais (DCNs), homologadas, definiram que o Ministério da Educação deveria coordenar o processo de elaboração do que o CNE denominou de Expectativas de Aprendizagem. Essa indicação aparece pela primeira vez nas Diretrizes Curriculares Nacionais do Ensino Fundamental (DCNEF).

Art. 49 O Ministério da Educação, em articulação com os Estados, os Municípios e o Distrito Federal, deverá encaminhar ao Conselho Nacional de Educação, precedida de consulta pública nacional, proposta de expectativas de aprendizagem dos conhecimentos escolares que devem ser atingidas pelos alunos em diferentes estágios do Ensino Fundamental (art. $9^{\circ}, \int 3^{\circ}$, desta Resolução) (BRASIL, 2010).

No entanto, repete-se nas Diretrizes Nacionais Curriculares do Ensino Médio (DCNEM):

Estas dimensões dão condições para um Ensino Médio unitário que, ao mesmo tempo, deve ser diversificado para atender com motivação à heterogeneidade e pluralidade de condições, interesses e aspirações dos estudantes. Mantida a diversidade, a unidade nacional a ser buscada, no entanto, necessita de alvos mais específicos para orientar as aprendizagens comuns a todos no país, nos termos das presentes Diretrizes. Estes alvos devem ser constituídos por expectativas de aprendizagem dos conhecimentos escolares da base nacional comum que devem ser atingidas pelos estudantes em cada tempo do curso de Ensino Médio, as quais, por sua vez devem necessariamente orientar as matrizes de competência do ENEM. Nesse sentido, o Conselho Nacional de Educação deverá apreciar proposta dessas expectativas, a serem elaboradas pelo Ministério da Educação, em articulação com os órgãos dos sistemas de ensino dos Estados, do Distrito Federal e dos Municípios (BRASIL, 2011, p. 188, grifos nossos).

O MEC, por intermédio da Secretaria de Educação Básica (SEB), coordenado pela Diretoria de Currículos e Educação Integral, inicia um processo de discussões, via Seminários e Grupos de Trabalho, e propõe inicialmente que não se parta do princípio da expectativa em relação à aprendizagem, mas sim do direito de o estudante aprender. 
A partir desse processo de discussão de 2011 a 2014, é elaborado o documento intitulado "Por uma política curricular para a educação básica: contribuição ao debate da base nacional comum a partir do direito à aprendizagem e ao desenvolvimento"(BRASIL, 2014), que embasou o início dos trabalhos; no entanto, com novas mudanças no MEC, não houve continuidade a partir dos princípios elencados.

\begin{abstract}
3.2. O Ministério da Educação, em articulação e colaboração com os entes federados e ouvida a sociedade mediante consulta pública nacional, elaborará e encaminhará ao Conselho Nacional de Educação (CNE), até o segundo ano de vigência deste PNE, proposta de direitos e objetivos de aprendizagem e desenvolvimento para os(as) alunos(as) de ensino médio, a serem atingidos nos tempos e etapas de organização deste nível de ensino, com vistas a garantir formação básica comum; 3.3. pactuar entre União, estados, Distrito Federal e municípios, no âmbito da instância permanente de que trata o $\int 5^{\circ}$ do art. $7^{\circ}$ desta lei, a implantação dos direitos e objetivos de aprendizagem e desenvolvimento que configurarão a base nacional comum curricular do ensino médio (BRASIL, 2014).
\end{abstract}

Nesse mesmo período, 2011-2014, conceitos e princípios aparecem nas primeiras versões do PNE 2014-2024, mas perdem o sentido quando são inseridos "direitos e objetivos de aprendizagem". Assim, a chamada "expectativa de aprendizagem" deu lugar, na BNCC, a "direitos e objetivos de aprendizagem". Embora as estratégias citadas no documento digam respeito ao ensino médio, a inserção do termo ocorre em todas as etapas da educação básica. É importante destacar que a LDB n. ${ }^{\circ}$ 9.394/1996 indicava no art. 26 que:

\begin{abstract}
Os currículos da educação infantil, do ensino fundamental e do ensino médio devem ter base nacional comum, a ser complementada, em cada sistema de ensino e em cada estabelecimento escolar, por uma parte diversificada, exigida pelas características regionais e locais da sociedade, da cultura, da economia e dos educandos (BRASIL, 1996, grifos nossos).
\end{abstract}

Apesar de a LDB, já em 1996, fazer referência à necessidade de se estabelecer uma Base Nacional Comum do currículo, foi somente depois de catorze anos que as Diretrizes trataram desse assunto.

A Secretaria de Educação Básica passa a realizar uma série de seminários com o intuito de estabelecer consensos em relação aos Direitos à Aprendizagem e desencadeia a discussão e elaboração por meio de Grupos de Trabalho, buscando a definição inicial do conceito.

Tomando expectativas de aprendizagem na perspectiva de um conjunto de obrigações
imputadas somente aos estudantes para a consolidação das tarefas, finalidades e resultados
escolares em um contexto de permanente culpabilização destes, de suas famílias e de seu
contexto sociocultural, o MEC, no ano de 2012, assume trabalhar esse documento em uma
perspectiva de direitos à aprendizagem e ao desenvolvimento. Esses por sua vez ensejam o
debate acerca das condições através das quais o Estado brasileiro tem garantido, ou não, as
possibilidades para que as tarefas, finalidades e resultados escolares sejam efetivados de modo
positivo na vida dos estudantes no cotidiano da instituição escolar (BRASIL, 2014, p. 7).

No entanto, no decorrer das mudanças e em meio às disputas internas no próprio MEC, o sentido foi se modificando e culminou na apresentação da primeira versão da BNCC para todas as etapas da educação básica, constituindo uma proposta de Base que mesclava direitos, objetivos e conteúdos. É interessante a capacidade de se apropriar de parte do vocabulário sem modificar em nada o seu conteúdo.

A primeira versão da BNCC foi apresentada em 2015, e, a pedido do Conselho de Secretários Estaduais de Educação (CONSED), o ensino médio foi retirado do conjunto de discussões da BNCC

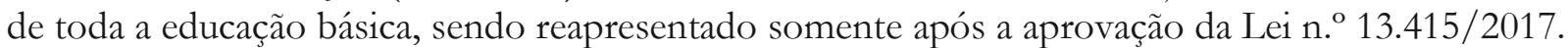

Para a definição da BNCC, os professores foram convidados a se manifestar, preenchendo um formulário eletrônico em que indicavam os conhecimentos que deveriam ser contemplados na etapa em que lecionavam. O atendimento ao convite possibilitou ao governo federal dizer que os professores haviam sido consultados e contribuiu para que estes confirmassem sua participação nesse processo. 
Consideramos, contudo, que a discussão específica sobre o assunto não foi viabilizada de forma ampla, envolvendo o coletivo de professores nas escolas, posto que tal consulta seguiu individualizada e sem uma preparação prévia.

Entendemos que a BNCC deve ser lida e analisada por todos os professores e pesquisadores que se interessam pelo ensino médio, já que traz elementos novos dentro de uma antiga proposta: a formação que privilegia o mercado. Para nós, embora se refira ao ensino médio, essa política se alinha a um conjunto de ações e a outras políticas, pois define os componentes curriculares obrigatórios, é parâmetro para a definição de formação inicial e continuada de docentes, é ligada à produção de material didático e é referência à política nacional de avaliação, constituindo-se, portanto, a nosso ver, como de interesse de todos os educadores.

\section{BNCC: ELEMENTOS DE SUA QUESTIONADA PROPOSTA}

A BNCC foi apresentada pelo Ministro Mendonça Filho como um documento plural que se inspira em experiências mundiais avançadas. Vejamos:

A partir dela, as redes de ensino e instituições escolares públicas e particulares passarão a ter uma referência nacional comum e obrigatória para a elaboração dos seus currículos e propostas pedagógicas, promovendo a elevação da qualidade do ensino com equidade e preservando a autonomia dos entes federados e as particularidades regionais e locais (BRASIL, 2018a, p. 5).

A BNCC é considerada pelo MEC como um documento que visa ao desenvolvimento de "aprendizagens essenciais", assegurando "os direitos de aprendizagem" (BRASIL, 2018a, p. 7). A Base não é apenas orientadora do currículo: é um documento que dá indicativos de outras alterações, como fica claro no excerto a seguir:

[...] a BNCC integra a política nacional da Educação Básica e vai contribuir para o alinhamento de outras políticas e ações, em âmbito federal, estadual e municipal, referentes à formação de professores, à avaliação, à elaboração de conteúdos educacionais e aos critérios para a oferta de infraestrutura adequada para o pleno desenvolvimento da educação (BRASIL, 2018a, p. 8, grifos nossos).

São comentados, ainda, conforme a BNCC, o direito à aprendizagem e o desenvolvimento de competências gerais, os quais, em conjunto, descrevem dez competências, que são a culminância das aprendizagens essenciais que não se restringem ao ensino médio; pelo contrário, são traçadas desde a educação infantil, perpassando o ensino fundamental e englobando o ensino médio. Nas indicações de tais competências, encontramos uma ampla proposta educativa que enfatiza: a perspectiva de uma educação inclusiva, o contexto de uma sociedade democrática, o interesse por um posicionamento ético e, também, a mobilização de conhecimentos para continuar aprendendo, para resolver problemas, para exercer o protagonismo e construir um projeto de vida, respeitando a diversidade. Esses aspectos estão, em grande parte, descritos na décima competência geral: "Agir pessoal e coletivamente com autonomia, responsabilidade, flexibilidade, resiliência e determinação, tomando decisões com base em princípios éticos, democráticos, inclusivos, sustentáveis e solidários” (BRASIL, 2018a, p. 10).

A BNCC, conforme explicitado, está fundamentada na Constituição Brasileira (1988), na Lei de Diretrizes e Bases da Educação Nacional - Lei n. ${ }^{\circ}$ 9.394/1996 -, nas Diretrizes Curriculares Nacionais Gerais para a Educação Básica e no Plano Nacional de Educação - Lei n. ${ }^{\circ}$ 13.005/2014. Com relação aos fundamentos pedagógicos, a Base destaca o desenvolvimento de competências e a educação integral independente do período da jornada escolar. Sobre a educação integral, é possível verificar indicações da proposta no documento:

Reconhece, assim, que a Educação Básica deve visar à formação e ao desenvolvimento humano global, o que implica compreender a complexidade e a não linearidade desse desenvolvimento, rompendo com visões reducionistas que privilegiam ou a dimensão intelectual (cognitiva) ou a 
dimensão afetiva. Significa, ainda, assumir uma visão plural, singular e integral da criança, do adolescente, do jovem e do adulto - considerando-os como sujeitos de aprendizagem - e promover uma educação voltada ao seu acolhimento, reconhecimento e desenvolvimento pleno, nas suas singularidades e diversidades. Além disso, a escola, como espaço de aprendizagem e de democracia inclusiva, deve se fortalecer na prática coercitiva de não discriminação, não preconceito e respeito às diferenças e diversidades (BRASIL, 2018a, p. 14, grifos nossos).

Segundo argumentos do MEC, trata-se de uma política que promete avanço para a educação brasileira, mas tem sido difícil para o governo sustentar a retórica quando a matéria é encaminhada para manifestações públicas. Isso porque é preciso estar muito comprometido com esta política para não perceber suas fragilidades e consequências danosas à educação pública brasileira. Em 2018, na Comissão Bicameral do Conselho Nacional de Educação, que trata sobre a Base Nacional Comum Curricular do EM, a maioria dos participantes, em especial no que se refere à hierarquização de componentes curriculares, itinerários formativos e formação docente, ratificou severas críticas, muitas preocupações e dúvidas sobre esse importante documento.

Quando o MEC encaminhou a BNCC ao Conselho Nacional de Educação (CNE), este programou cinco audiências públicas para "colher subsídios e contribuições para a elaboração da norma instituidora da Base Nacional Comum Curricular - Ensino Médio" (BRASIL, 2018, Art. $3^{\circ}$ ). As audiências seriam presididas pelo Presidente da Comissão Bicameral, Cesar Callegari, que analisaria a BNCC. A primeira audiência ocorreu em 11 de maio de 2018, em Florianópolis, e contou com ampla representação de segmentos da educação, majoritariamente contrários à reforma e ao texto da BNCC. A segunda audiência, agendada para 8 de junho de 2018, foi suspensa em decorrência de protestos contra a reforma do ensino médio.

No dia 29 de julho de 2018, o conselheiro Callegari, que coordenou os trabalhos da Comissão que aprovou a BNCC do ensino fundamental e que coordenava a Comissão da BNCC do ensino médio, publica uma Carta aos conselheiros do Conselho Nacional de Educação, na qual anuncia e justifica a sua saída da presidência da Comissão.

$\mathrm{Na}$ referida carta, conclui que a BNCC não pode ser discutida em separado da Lei n. ${ }^{\circ}$ 13.415/2017, que se originou pela Medida Provisória, e observa que uma está estreitamente ligada à outra. Afirma ele: "A própria Lei é clara ao estabelecer que é a BNCC que lhe dará "corpo e alma". Problemas da Lei contaminam a BNCC. Problemas da Base incidirão sobre a Lei”. (CALLEGARI, 2018, p. 2)

Destaca-se que Callegari (2018) se junta ao conjunto de vozes (professores da educação básica do ensino superior, estudantes e entidades) que, nas audiências, vêm denunciando o desmonte que se está tentando impor à educação pública brasileira, a despeito da promessa sedutora do MEC em torno da qualidade prometida, da liberdade de escolha, da possibilidade de o jovem definir o seu projeto de vida ao fazer a "escolha" dos itinerários formativos.

Os elementos apresentados deixam claro que a trajetória da BNCC merece ser aprofundada e conhecida pelos educadores que vão implementar as alterações curriculares nas escolas, porque tais elementos se entrelaçam a interesses formativos que visam à manutenção da educação desigual, em conformidade com o projeto societário neoliberal.

A terceira audiência ocorreu em Fortaleza, em 05 de julho de 2018, sob muitos protestos, e a quarta, programada para 10 de agosto de 2018, em Belém, foi tomada pelos manifestantes, que realizaram um debate aberto com a comunidade, com a participação, na plateia, de alguns conselheiros que já haviam se manifestado contra a reforma e a BNCC - dentre eles, o ex-presidente da Comissão. A quinta audiência pública foi realizada em Brasília, em 10 de setembro de 2018, com amplo aparato de segurança. Depreende-se do exposto o quanto essa proposta desencadeia incômodo e repúdio por diversas pessoas, entidades e alguns membros do CNE; é importante lembrar que, se a BNCC não fosse aprovada, a Lei n. ${ }^{\circ}$ 13.415/2017, dependente da Base Comum, ficaria praticamente inconclusa.

Deve-se enfatizar ainda que o alinhamento da proposta em curso não se explica apenas internamente. Urge entender as vinculações externas ao que é proposto no âmbito da educação brasileira, questão sobre a qual nos deteremos a seguir. 


\section{INSPIRAÇÕES PARA A PROPOSIÇÃO DO 'NOVO’ CURRÍCULO}

A política educacional brasileira vem se desenvolvendo com forte interferência de sugestões e condicionantes de organismos internacionais como a UNESCO, o Banco Mundial, a CEPAL e a OCDE. Esse assunto foi pauta da discussão de pesquisadores como Fonseca (1996), Leher (1999) e Deitos (2003), dentre outros, que analisaram tanto o direcionamento dado às políticas educacionais, como também os resultados que passavam a ser requeridos da escola e da educação. Eles destacaram como os direcionamentos dados pelas agências e organizações internacionais são propostos, entrelaçados aos projetos de governos com traços neoliberais. As proposições para a educação básica (ensino fundamental e médio), para a educação profissional e para a educação superior corresponderam a interesses formativos que objetivavam a formação cada vez mais sob responsabilidade dos indivíduos, com fortes traços da teoria do capital humano, com inspiração na formação de profissionais voltados para atendimento ao mercado.

Podemos inferir, com base na leitura dos autores supracitados, que os organismos internacionais, ao firmarem acordo de cooperação e concederem empréstimos aos países, combinam também o desenvolvimento de propostas baseadas em seus pressupostos. Este não é um processo de mão única, mas combinado com membros, funcionários que se encontram nos processos de negociação com tais organismos. Entendemos que é desse modo que se firmam acordos de cooperação técnica, financeira e ideológica.

Os aspectos comentados até o momento são importantes para pensarmos os atuais acordos de cooperação e o papel de organismos internacionais que não estabelecem acordos financeiros, mas sugestionam projetos educativos e propagam uma visão de mundo, de educação e de homem a ser formado. A desvalorização do conhecimento, como um ato programado da política educacional, ao menos para um segmento da população, foi objeto de análise de Libâneo (2012), que discute as consequências de trinta anos de uma política que promoveu o agravamento da dualidade da escola pública atual: uma escola do conhecimento para os ricos e uma escola do acolhimento social para os pobres. Segundo ele:

[...] agravamento da dualidade da escola pública brasileira atual, caracterizada como uma escola
do conhecimento para os ricos e como uma escola do acolhimento social para os pobres. Esse
dualismo, perverso por reproduzir e manter desigualdades sociais, [...] está em consonância com
os acordos internacionais em torno do movimento Educação para Todos, cujo marco é a
Conferência Mundial sobre Educação para Todos, realizada em Jomtien, na Tailândia, em 1990,
sob os auspícios do Banco Mundial, do Programa das Nações Unidas para o Desenvolvimento
(PNUD), do Fundo das Nações Unidas para a Infância (UNICEF) e da Organização das Nações
Unidas para a Educação e Cultura (UNESCO). Com base em pesquisa bibliográfica, este estudo
argumenta que a associação entre as políticas educacionais do Banco Mundial para os países em
desenvolvimento e os traços da escola dualista representa substantivas explicações para o
incessante declínio da escola pública brasileira nos últimos 30 anos (LIBÂNEO, 2012, p. 13,
grifos nossos).

Os estudos de Libâneo (2016) permitem dizer que o currículo norteado pelas sugestões dos organismos internacionais é instrumental e orientado por resultados imediatistas e, com isso,

[...] tudo o que importa seria estabelecer níveis desejáveis de aquisição de conhecimentos, ou seja, uma lista de competências e um sistema de avaliação de desempenho que comprove aprendizagem, no sentido de formar sujeitos produtivos visando a empregabilidade imediata (LIBÂNEO, 2016, p. 48).

Nesse sentido, conforme lembrou o autor, perdem espaço o professor, a formação de professores e a escola, que tem sua função social intencionalmente alterada, aumentando-se o fosso da dualidade escolar e social. Por isso, destaca-se a formação inicial e continuada de professores, apontada como ação imprescindível para a exequibilidade da proposta; enfatiza-se a valorização de experiências de 
sucesso no desenvolvimento da base, como reconhecimento de boas práticas que explicitam, sobretudo, o saber fazer do professor, assim como se realçam os modelos educativos bem-sucedidos.

Esses são alguns traços característicos do que vem sendo proposto, reivindicações como a formação a partir do desenvolvimento de competências, a necessidade de contemplar, nas propostas pedagógicas, habilidades requeridas pelo mercado, o desenvolvimento de uma formação em que a ideia da adaptação ao mercado precisa ser considerada e valorizada como aspecto importante para se formar o capital humano.

A formação adaptada ao mercado pode ser vista nos estudos de Pereira (2018, p. 111), para quem:

A OCDE atua combinando políticas de crescimento econômico, mercados competitivos e educação, por entender que esta é a chave para a reprodução do capital. A Organização atua e direciona o processo de globalização econômica e de reestruturação do capital, contribuindo para o processo de ressignificação da teoria do capital humano, formulando e implementando propostas que buscam adaptar as políticas educativas às demandas oriundas do mercado de trabalho.

As indicações para formação, presentes na reforma do ensino médio pela BNCC, estão em sintonia com o que preconiza a OCDE para o desenvolvimento da educação com inspiração capitalista, visando tanto a um modelo de formação, quanto a um modelo de escola, como podemos verificar em Pereira:

Essa concepção de educação assenta-se em quatro eixos, a saber: i) assemelhar escolas com empresas, com o intuito de oferecer uma formação polivalente, centrada em conhecimentos rudimentares; porém, úteis ao mercado de trabalho; ii) tratar a educação como treinamento e instrução de competências e habilidades individuais, estimulando a competitividade; iii) exigir, por meio de avaliações externas, as características de escola-empresa no quase-mercado educacional, objetivando a exigência de alunos preparados e adaptados às demandas do mercado; e iv) exigir e responsabilizar os estudantes e jovens pela aquisição das destrezas necessárias aos padrões capitalistas de empregabilidade (PEREIRA, 2018, p. 111).

As indicações de alteração da avaliação, propostas na BNCC, são também concretizadas em consonância com as intenções da OCDE. É também prioridade da OCDE a avaliação em larga escala, que classifica o estudante com base em suas habilidades e competências e valoriza conhecimentos centrais na BNCC, conforme podemos verificar em Frigotto e Motta (2017) ao se referirem à visão dos reformadores sobre o currículo do ensino médio, e, também, no trecho descrito por Pereira (2018, p. 111).

O Pisa é um inquérito internacional que verifica níveis de aprendizagem dos estudantes de 15 anos, em Leitura, Matemática e Ciências. Teve sua primeira aplicação em 2000, centrada em Leitura e, desde então, é aplicado a cada três anos, dando prioridade $(70 \%)$ para cada uma das áreas em seu ciclo. Segundo a OCDE (2007), a prioridade do Pisa é identificar as competências e habilidades dos estudantes que estão no processo de transição para vida produtiva e, por isto, tais destrezas precisam estar em sintonia com as questões que a sociedade (de mercado) demanda. Neste sentido, a categoria competências e habilidades assume preponderância política nos documentos que trazem análises sobre o programa. Este fato também revela os interesses de um sistema de verificação em larga escala, como o empreendido pela Organização.

Nos dados apresentados, detecta-se a presença de uma política minimalista para o ensino médio, voltada à formação de capital humano, mediante o desenvolvimento de competências, política esta que define a função utilitária da escola e o lugar que os estudantes deverão ocupar na estrutura social para a perpetuação da exploração econômica. Essa tendência minimalista, como vimos, ganhou terreno na reforma educacional dos anos 1990.

Na discussão sobre os limites epistemológicos, pedagógicos e metodológicos das orientações curriculares para a educação profissional baseada em competências, Ramos (2002, p. 413) comenta sobre 
a "concepção (neo)pragmática de conhecimento", no que se refere ao conhecimento escolar, que, à época, se colocava como uma tendência na reforma educacional profissional:

Se em relação ao conhecimento se dissolvem as fronteiras entre conceito científico e conceito cotidiano, em relação às aprendizagens prevalece o senso comum ou o condutivismo, por se associar uma concepção superficial do (neo)pragmatismo à formulação que reduz as competências aos procedimentos" (RAMOS, 2002, p. 413, grifos nossos).

A tríade da reforma apontada neste texto não rompe com essa tendência, mas a agrava ainda mais ao eleger a supremacia das competências, em detrimento do conhecimento, sobretudo no que concerne à capacidade de agir, exercitar, argumentar, escolher, cuidar e valorizar em determinadas situações - todas essas ações pautadas pelo imediatismo. Não por acaso, o notório saber foi introduzido pela Lei n. ${ }^{\circ}$ 13.415/2017. Além disso, as áreas de conhecimento encontram-se diluídas nos itinerários formativos. As DCNEM reforçam esse movimento e retomam os objetivos das diretrizes aprovadas na década de 1990, Parecer n. ${ }^{\circ}$ 03/1998.

Observa-se que, desde as reformas educacionais dos anos 1990, no contexto de políticas neoliberais, o mantra da reforma educacional se concentra na justificativa econômica para a educação, cuja consequência é o abandono do compromisso com as instituições públicas. Para Bastos (2017, p. 96), com a aceitação da predominância econômica da educação, está-se "[...] descurando de sua perspectiva cívica, moral e civilizatória".

As reformas em curso desde 2016 no Brasil têm adotado "austeridade fiscal e de precariedade, flexibilização e descartabilidade da força de trabalho" (BASTOS, 2017, p, 94) enquanto ajuste necessário para escapar da atual crise do capital iniciada em 2008. Para este autor, tal processo é resultado da concentração financeirizada, que passa a impor aos governos a adoção desses ajustes.

Como se constata, o mais dramático dessa lógica são a estagnação, a exclusão e a descartabilidade da força de trabalho e de um segmento da população. Nesse raciocínio, Bastos (2017, p. 96), apoiando-se nas análises de Blacker sobre o "eliminacionismo educacional", vê nas reformas educacionais em curso uma tendência a diferenciar o investimento em educação para um segmento da população, considerado ilucrável, portanto, tido como descartável, a quem não caberia qualquer tipo de investimento nessa área. Para este grupo, segundo Bastos (2017, p. 98), as "necessidades pedagógicas e de desenvolvimento humano e social do alunado" passariam a dar lugar a um "caráter imediatista, mercantilizante e adestrador" aos limites das necessidades de manutenção da ordem estabelecida, leia-se nova governança.

\section{CONSIDERAÇÕES FINAIS}

Vivemos num momento peculiar da história da política educacional brasileira, não pela novidade que traz, mas, sobretudo, pela capacidade de aglutinar, acentuar e atualizar uma tendência minimalista que tomou corpo na reforma educacional dos anos 1990, a saber: no campo curricular, o praticismo e o presentismo - cujo conhecimento se definiria na peculiaridade do que se considera "socialmente útil" a determinado segmento da população - que, a partir do ideário neoliberal, definem o processo formativo com estreita ligação com as demandas de formação do "novo" trabalhador.

Apresentam ênfase no currículo, como o responsável por mudanças quantitativas em relação aos parâmetros utilizados para medir qualidade, sem levar em conta as condições necessárias para que o processo de aprendizagem ocorra, não tendo a centralidade do processo nos alunos, na garantia do direito ao conhecimento, mas, sim, no que dele se espera.

As consequências perversas dessa tendência estariam debitadas ao próprio sujeito jovem, pela "escolha" equivocada de determinado "projeto de vida". Passa-se, então, a acreditar que a aprendizagem resulta unicamente da vontade e da boa escolha do sujeito, constituindo-se independente de todas as condições de materialidade da vida.

Essas propostas reformadoras, já amplamente discutidas por vários autores, têm sofrido forte influência tanto de grupos empresariais, que buscam configurar a formação da juventude brasileira, quanto de grupos que têm interesse no fortalecimento das avaliações em larga escala, sejam elas 
internacionais ou nacionais, e na produção de materiais. Disso resulta, conforme discutimos, um processo de padronização curricular, estreitamente adequado à venda de material pedagógico, livros e pacotes tecnológicos.

Para que esta conformação ocorra, há uma estreita ligação entre as políticas: de currículo (BNCC); de formação dos jovens; de formação dos professores e das avaliações em larga escala. No processo de padronização e minimização curricular, de adequação da formação docente às novas demandas das avaliações, observa-se a abertura de ganhos com a produção de materiais: livros e Kits pedagógicos.

O docente mais adequado a essa tendência é o adaptável, cuja formação inicial e continuada se adequa às demandas mais imediatas e se volta para a prática e a desvalorização do conhecimento teórico, o que resulta na possibilidade de que sua formação tenha custos menores e se processe de forma mais rápida.

Essa reforma representa uma reedição ainda mais perversa da reforma educacional implementada nos anos 1990 porque abandona o jovem à sua própria sorte. A reforma do ensino médio, hoje, longe de constituir uma ruptura em relação ao que fora estabelecido, assemelha-se à segunda fase da mesma proposta; assim, acentuando-se o foco para a juventude, a promessa agora é a de que o jovem decidirá precocemente "o seu projeto de vida", a partir, evidentemente, das delimitadas possibilidades de escolhas, e para o qual as suas condições sociais e econômicas serão determinantes.

Em relação à escola, esvazia-se ainda mais o conhecimento escolar, condição para aligeirar e fragmentar a formação e a carreira docente. Dado o constrangimento de financiamento imposto pela Emenda Constitucional n. ${ }^{\circ}$ 095/2016, as escolas públicas, sem opção, ainda que com muita vontade, poderão incorrer em ações improvisadas, as quais terão o mérito de rebaixar ainda mais o ensino público.

A consequência mais perversa dessa reforma, cuja elaboração se encontra estreitamente aninhada em três instrumentos - Lei n. ${ }^{\circ}$ 13.415/2017, BNCC e DCNEM -, é a construção de uma formação que se fixa no presentismo, no utilitarismo, no imediatismo que tem como resultado a perda da perspectiva do sujeito jovem enquanto ser social, enquanto um sujeito com "determinada origem familiar, que ocupa um determinado lugar social e se encontra inserido nas relações sociais" (DAYRELL, 2003, p. 43). Tal condição é imprescindível para que o segmento jovem assuma os fracassos como determinantes de suas próprias "escolhas", de forma que as relações de produção material fiquem intocáveis no atual regime de acumulação do capitalismo.

\section{REFERÊNCIAS}

BASTOS, Remo Moreira Brito. No profitleftbehind: os efeitos da economia política global sobre a educação básica pública. 2017. Tese (Doutorado em Educação Brasileira) - Universidade Federal do Ceará, Fortaleza, 2017. Disponível em: http://www.repositorio.ufc.br/handle/riufc/28494. Acesso em: 15 jul. 2018.

BRASIL. Ministério da Educação. Lei n. ${ }^{\circ}$ 9.394, de 20 de dezembro de 1996. Estabelece as diretrizes e bases da educação nacional. Brasília: Presidência da República, 1996. Disponível em: http://www.planalto.gov.br/ccivil_03/leis/L9394.htm. Acesso em: 15 mar. 2016.

BRASIL. Ministério da Educação. Resolução n. ${ }^{\circ}$ 7, de 14 de dezembro de 2010. Fixa Diretrizes Curriculares Nacionais para o Ensino Fundamental de 9 (nove) anos. Brasília: MEC, 2010. Disponível em: http://portal.mec.gov.br/dmdocuments/rceb007_10.pdf. Acesso em: 5 set. 2018.

BRASIL. Ministério da Educação. Parecer n. ${ }^{\circ}$ 5/2011. Assunto: Diretrizes Curriculares Nacionais para o Ensino Médio. Brasília: MEC, 2011. Disponível em:

http://portal.mec.gov.br/index.php?option=com_docman\&view=download\&alias=9915-pceb005-111-1\&Itemid=30192. Acesso em: 5 set. 2018. 
BRASIL. Ministério da Educação. Por uma política curricular para a educação básica: contribuição ao debate da base nacional comum a partir do direito à aprendizagem e ao desenvolvimento. Documento em versão Preliminar. Brasília: MEC, 2014.

BRASIL. Emenda Constitucional n. 95 de 15 de dezembro de 2016. Altera o Ato das Disposições Constitucionais Transitórias para instituir o Novo Regime Fiscal, e dá outras providências. Brasília: Presidência da República, 2016a. Disponível em: http://www.planalto.gov.br/ccivil_03/constituicao/emendas/emc/emc95.htm. Acesso em: 20 abr. 2018.

BRASIL. EM n. ${ }^{\circ}$ 00084/2016/MEC. Brasília, 2016b. Disponível em: http://www.planalto.gov.br/ccivil_03/_ato2015-2018/2016/Exm/Exm-MP-746-16.pdf. Acesso em: 5 set. 2018.

BRASIL. Medida Provisória n. ${ }^{\mathbf{0}}$ 746, de 22 de setembro de 2016. Institui a Política de Fomento à Implementação de Escolas de Ensino Médio em Tempo Integral, altera a Lei n. ${ }^{\circ}$ 9.394, de 20 de dezembro de 1996, que estabelece as diretrizes e bases da educação nacional, e a Lei n. ${ }^{\circ} 11.494$ de 20 de junho 2007, que regulamenta o Fundo de Manutenção e Desenvolvimento da Educação Básica e de Valorização dos Profissionais da Educação, e dá outras providências. Brasília: Câmara dos Deputados, 2016c. Disponível em: https://www2.camara.leg.br/legin/fed/medpro/2016/medidaprovisoria-74622-setembro-2016-783654-exposicaodemotivos-151127-pe.html. Acesso em: 9 dez. 2019.

BRASIL. Parecer n. ${ }^{\mathbf{9}}$ 95, de 2016. Comissão Mista da MPV 746/2016, sobre a Medida Provisória n. ${ }^{\circ}$ 746, de 2016. Brasília: Senado Federal, 2016d. Disponível em:

http://www.camara.gov.br/proposicoesWeb/prop_mostrarintegra;jsessionid=AF377D2235A0BD98C 552DA137E502EA6. Acesso em: 26 ago. 2018.

BRASIL. Lei n. $^{\mathbf{1}} \mathbf{1 3 . 4 1 5}$, de $\mathbf{1 6}$ de fevereiro de 2017. Altera as Leis n. ${ }^{\circ}$ 9.394, de 20 de dezembro de 1996, que estabelece as diretrizes e bases da educação nacional, e 11.494, de 20 de junho 2007, que regulamenta o Fundo de Manutenção e Desenvolvimento da Educação Básica e de Valorização dos Profissionais da Educação, a Consolidação das Leis do Trabalho - CLT, aprovada pelo Decreto-Lei n. ${ }^{\circ}$ 5.452, de $1^{\circ}$. de maio de 1943, e o Decreto-Lei n. ${ }^{\circ} 236$, de 28 de fevereiro de 1967; revoga a Lei n. ${ }^{\circ}$ 11.161, de 5 de agosto de 2005; e institui a Política de Fomento à Implementação de Escolas de Ensino Médio em Tempo Integral. Brasília: Presidência da República, 2017. Disponível em:

http://www.planalto.gov.br/ccivil_03/_ato2015-2018/2017/lei/113415.htm. Acesso em: 21 abr. 2018.

BRASIL. Ministério da Educação. Base Nacional Comum Curricular: educação é a base: ensino médio, 2018a. Disponível em:

http:/ / portal.mec.gov.br/index.php?option $=$ com_docman\&view $=$ download\&alias $=79601$-anexotexto-bncc-reexportado-pdf-2\&category_slug=dezembro-2017-pdf\&Itemid=30192. Acesso em: 5 set. 2018.

BRASIL Ministério da Educação. Resolução n. ${ }^{\circ}$ 3, de 21 de novembro de 2018. Atualiza as Diretrizes Curriculares Nacionais para o Ensino Médio. Brasília: MEC, 2018b. Disponível em: http://novoensinomedio.mec.gov.br/resources/downloads/pdf/dcnem.pdf. Acesso em: 13 ago. 2019.

CALLEGARI, Cesar. Carta aos conselheiros do Conselho Nacional de Educação. Brasília, 2018. Disponível em: https://avaliacaoeducacional.files.wordpress.com/2018/06/carta-aos-conselheiros-docne.pdf. Acesso em: 5 jul. 2018.

CUNHA, Luis Antônio. Educação e desenvolvimento social no Brasil. Rio de Janeiro: Francisco Alves, 1986. 
CUNHA, Luis Antônio. Ensino médio: atalho para o passado. Educação \& Sociedade, Campinas, v. 38, n. 139, p.373-384, abr./jun. 2017. doi: doi.org/10.1590/es0101-73302017176604.

DAYRELL, Juarez. O jovem como sujeito social. Revista Brasileira de Educação. Rio de Janeiro, n. 24, p. 40-52, set/dez 2003. Disponível em: http://www.scielo.br/pdf/rbedu/n24/n24a04.pdf. Acesso em: 9 dez. 2019.

DEITOS, Roberto A. A política educacional paranaense para o ensino médio e profissional (19952002): o PROEM e as recomendações do BID e Banco Mundial. In: NOGUEIRA, Francis M. G.; RIZZOTTO, Maria L. F. (org.). Estado e políticas sociais: Brasil-Paraná. Cascavel: EDUNIOESTE, 2003. p. 101-118.

FONSECA, Marília. O financiamento do Banco Mundial à educação brasileira: vinte anos de cooperação internacional. In: TOMMASI, Livia; EARDE, Miriam J.; HADDAD, Sérgio. (org.). $\mathbf{O}$ Banco Mundial e as políticas educacionais. São Paulo: Cortez, 1996. p. 229-251. Disponível em: http://outubrorevista.com.br/wp-content/uploads/2015/02/Revista-OutubroEdic\%CC\%A7a\%CC\%83o-3-Artigo-03.pdf. Acesso em: 27 abr. 2018.

FRIGOTTO, Gaudêncio; MOTTA, Vânia Cardoso. Por que a urgência da reforma do ensino médio? Medida Provisória 746/2016 (Lei 13.415/2017). Educação \& Sociedade, Campinas, v. 38, n. 139, p. 355-372, abr./jun. 2017. Disponível em: http://www.scielo.br/pdf/es/v38n139/1678-4626-es-38-13900355.pdf. Acesso em: 15 ago. 2018.

LEHER, Roberto. Um novo senhor da educação? A política educacional do Banco Mundial para a periferia do capitalismo. Revista Outubro, São Paulo, v. 1, n.3, p. 19-30, 1999.

LIBÂNEO, José Carlos. O dualismo perverso da escola pública brasileira: escola de conhecimento para os ricos, e escola de acolhimento social para os pobres. Educação e Pesquisa, São Paulo, v. 38, n. 1, p. 13-28, 2012.

LIBÂNEO, José Carlos. Políticas educacionais no Brasil: desfiguramento da escola e do conhecimento escolar. Cadernos de Pesquisa, São Paulo, v. 46, n. 159, p. 38-62, jan./mar.2016.

PEREIRA, Rodrigo da Silva. Avaliação de sistemas e política de competências e habilidades da OCDE. Revista Práxis Educativa, Ponta Grossa, v. 13, n. 1, p. 107-127, jan./abr. 2018. Disponível em: http://www.revistas2.uepg.br/index.php/praxiseducativa. Acesso em: 26 abr. 2018.

RAMOS, Marise Nogueira. A educação profissional pela Pedagogia das Competências: para além da superfície dos documentos oficiais. Educação \& Sociedade, Campinas, v. 23, n. 80, set. 2002. Disponível em: http://escoladegestores.mec.gov.br/site/8-biblioteca/pdf/mn_ramos.pdf. Acesso em: 10 maio 2018. 